\title{
Osmotic cataract causes reduced vision in wild Atlantic salmon postsmolts
}

\author{
Ellen Bjerkås ${ }^{1, *}$, Jens Christian Holst ${ }^{2}$, Inge Bjerkås ${ }^{1}$, Amund Ringvold ${ }^{3}$ \\ ${ }^{1}$ Norwegian School of Veterinary Science, PO Box 8146 Dep, 0033 Oslo, Norway \\ ${ }^{2}$ Institute of Marine Research, PO Box 1870 Nordnes, 5817 Bergen, Norway \\ ${ }^{3}$ Department of Ophthalmology, National Hospital, University of Oslo, 0027 Oslo, Norway
}

\begin{abstract}
Osmotic cataracts were diagnosed in all of 191 Atlantic salmon Salmo salar L. postsmolts caught during 8 trawl hauls on the western side of the Vøringsplateau, Norwegian Sea, in June 2001. The changes varied from a hazy opacity in the anterior part of the lens to cataracts affecting the whole lens. Severely affected lenses appeared swollen and large vacuoles were visible in the opaque areas. Large vacuoles in otherwise clear lenses were diagnosed in 1 of 4 adult salmon examined. Histologically, widened sutures, vacuolation of lens epithelium and cortex, and proteinaceous lakes subjacent to the epithelium were the most frequent changes, while extensive cortical necroses and epithelial proliferation were seen in a few cases. UV-absorbance of the aqueous humor was determined and levels compared to plasma levels and also to levels in farmed Atlantic salmon of the same developmental stage. Wild salmon generally showed higher levels of protective factors than farmed fish. The osmotic type of cataract diagnosed leads to poor vision and is a potential cause of reduced survival in postsmolts. The cause of the cataracts could not be determined, but defective osmoregulation is suspected.
\end{abstract}

KEY WORDS: Salmon · Eye $\cdot$ Cataract $\cdot$ Osmotic cataracts $\cdot$ UV-absorbance $\cdot$ Salmo salar

\section{INTRODUCTION}

'Cataract' is a common disease in farmed Atlantic salmon Salmo salar L. in Northern Europe, causing large economic losses due to reduced growth and increased mortality in affected fish (Breck \& Sveier 2001). Several factors contributing to cataract development have been identified in farmed fish, including rapid growth (Bjerkås et al. 1996, Waagbø et al. 1996), variation in water temperature (Bjerkås \& Bjørnestad 1999, Bjerkås et al. 2001) and nutritional deficiencies (Hughes 1985, Hargis 1991). Metabolic changes during the period of smoltification are considered to be involved in cataract development, although the exact mechanism has not been identified (Waagbø et al. 1996). Cataract induced by exposure to UV radiation has been reported in the rainbow trout Onchorhynchus mykiss (Cullen \& Monteith-McMaster 1993, Cullen et al. 1994). It is generally agreed that high solar UV irradiance levels in the environment would increase the risk of cataract in humans (Cruickshanks et al. 1992, Kerr \& McElroy 1993). In diurnal animals, the aqueous humor protects the lens against ambient radiation through 3 different mechanisms: absorption, fluorescence-quenching and fluorescence-mediated transformation (Ringvold 1996). The most significant UV-absorbing components in the aqueous humor of mammals and birds are ascorbate, urate and some amino acids, including tryptophane and tyrosine. High levels of ascorbate in the aqueous humor reduce UV-Binduced damage to the lens epithelium (Reddy et al. 1998). Little is known about UV-protection of the salmon lens. Since salmon are adapted to swimming in surface water, one would expect the salmon lens to have sufficient protection against UV radiation under normal conditions. It has, however, been hypothesised that increased UV irradiation caused by thinning of the ozone layer may be involved in cataract formation in 
the wild salmon, as exposure to ultraviolet light is a well-known cause of cataract in both humans and animals in general (Cruickshanks et al. 1992, Ayala et al. 2000, Oriowo et al. 2001).

Regardless of the primary cause(s), structural changes in the lens fibres will lead to cataracts. In farmed salmon, cataracts may present themselves as irreversible destruction of lens fibres and proliferation of lens epithelium around the anterior lens pole, but opacity of the lens due to osmotic changes is also known. Exposing parr to saltwater leads to an osmotic cataract that is visible as a hazy opacity around the anterior suture line due to swelling of lens fibres (Iwata et al. 1987). In severe cases, the whole lens may be affected. Precise regulation of lens hydration is critical for the maintenance of lens transparency, and lens hydration can be significantly higher in a certain form of cataract, termed an osmotic cataract. An osmotic cataract is reversible if the swelling is not of too long standing or has not caused disruption of fibres (Phelps Brown \& Bron 1996). The lens acts as a perfect osmometer, swelling in hypoosmotic solutions and shrinking in hyperosmotic solutions. Initially, the activity of the cation pumps compensates for the environmental changes, but eventually, the fibre membrane permeability breaks down, the sodium pump is inhibited and both the water and electrolyte content of the fibre increases. Cell swelling, cell shrinkage or enlargement of the extracellular spaces result in disruption of the highly ordered arrangement of lens fibres, causing light scatter clinically observed as cataract (Phelps Brown \& Bron 1996).

Unpublished reports show that irreversible cataract may occur also in wild salmon (T. Wall pers. comm., E.B. pers. obs.). Invasion with trematodes Diplostomum sp. causing a secondary cataract has been diagnosed in salmon returning to the Namsen river in Norway (P. Midtlyng pers. comm.). During seagoing salmon investigations carried out by the Institute of Marine Research, Bergen, Norway, in the Norwegian Sea over the last $10 \mathrm{yr}$, opacification of the lenses in wild postsmolt salmon has frequently been observed. Preliminary investigations of the phenomenon during the early 1990s dismissed the observations as postmortem changes; however, the ocular changes in a significant number of wild postsmolt salmon were observed even after IMR started catching live postsmolts by trawl and trawl cage in 1997. The opacities were hazy, extending over most of the lens (J.C.H. pers. obs.). Opaque eyes in salmon were also observed during a 1986 research cruise, although the nature of the opacities was not determined. Many of the salmons examined had fully or partly opaque eyes, suggesting some degree of reduced vision, and both reared and wild fish were affected. However, the ocular changes were not further studied. This condition was observed in live fish when using sets of drifting long lines and was not due to hooking injury, as most of the fish were hooked in the throat. No sign of parasites or any abrasion of the exterior surface of the eyes were found (Anonymous 1986).

Salmon depend on vision for normal food intake, and in aquaculture it has been shown that even salmon with moderate cataract changes have a reduced growth rate (Breck \& Sveier 2001). Wild salmon with a cataract could be expected to face problems in finding food and may also be easy prey. Cataracts in wild salmon are therefore expected to cause both reduced growth and reduced survival, and could potentially have serious negative effects on the population. During the last years, the number of wild salmon in many Norwegian rivers has declined (Staurnes et al. 1996). The cause may be multifactorial, but it seems reasonable to believe that cataracts represent a significant mortality factor in postsmolts.

The present investigation was carried out to study and describe cataract changes in wild postsmolts caught in the Norwegian Sea. Different etiological factors are considered, including the possible impact of UV radiation.

\section{MATERIALS AND METHODS}

A total of 191 postsmolt salmon Salmo salar, ranging in weight from 36 to $189 \mathrm{~g}$ and in length from 146 to $264 \mathrm{~mm}$, were collected during 8 trawl hauls with the RV 'Johan Hjort' on the western side of the Vøringplateau in the Norwegian Sea in June 2001. Based on the size and knowledge of the migratory pattern of this species, the postsmolts were determined to be of British and Norwegian origin. The salmon were mixed with large numbers of mackerel. Fish not already dead in the trawling nets were killed with a light blow to the head immediately prior to eye examination. In addition to the postsmolts, 4 adult salmon caught in the same area were examined.

The eyes were examined with a KOWA SL-5 slitlamp biomicroscope under darkened conditions. Routine screening included examination of the anterior structures of the eye, as well as description and grading of the cataract. Each eye was evaluated separately, quantifying cataract changes according to the grading system described by Wall \& Bjerkås (1999): A normal lens was given Score 0, while Score 4 represented a lens with a complete cataract, causing blindness of the affected eye. The maximum score for both eyes in 1 fish was 8 . The eventual presence of intraocular hemorrhage was also recorded. The lens changes were documented with a KOWA RL fundus camera. Aque- 
ous humor was collected from the anterior chamber of 17 smolts by use of a $1 \mathrm{ml}$ tuberculin syringe and a 25-gauge needle and transferred to a cryo tube (Cryo Systems). Four pooled samples of 4 to 5 fish were immediately frozen until analysis. Blood samples were taken from the caudal vein from the same fish with a 2 $\mathrm{ml}$ syringe and a 21-gauge needle, and transferred to 2 $\mathrm{ml}$ heparinised Vacutainer tubes. Plasma was obtained after centrifugation $(1500 \times g, 10 \mathrm{~min})$ and frozen at $-20^{\circ} \mathrm{C}$ until analysis. Whole eyes from 20 smolts were carefully dissected and fixed in 10\% nonbuffered formalin for histopathology. In addition, 25 mackerel Scomber scombrus caught in the same trawlings were screened on-site for ocular changes.

Total protein in the aqueous humor and plasma was determined using a microprotein assay (Procedure no. 610; Sigma). Ascorbic acid and uric acid levels in plasma and aqueous humor were determined by mixing equal volumes of metaphosphoric acid, 100 and $50 \mathrm{~g}$ $\mathrm{l}^{-1}$, respectively, before testing with high-performance liquid chromatography (HPLC) (Ringvold et al. 1998). The amino acid concentrations were measured with an automatic amino acid analyser (Eppendorf/Biotronik LC 3000). Based on phosphate buffer (0.1 M, pH 7.3) mock aqueous humor was mixed according to the component values in Table 1. Apart from total protein, which was added as bovine albumin, Sigma products were used. Absorbance was measured with an Hitachi spectrophotometer (U 2000) and quartz cuvettes with a $2 \mathrm{~mm}$ light pathway. UV-absorbance of the wild salmon aqueous humor was compared to that from farmed postsmolts of the NLA (Norsk Lakseavl) strain using 2 pooled samples of aqueous humor each from 5 salmon farmed under normal conditions and collected in the same manner as for the wild salmon. The prevalence of cataracts in the farmed salmon sampled was not known.

Table 1. Salmo salar. Levels of UV-absorbing components in aqueous humor and serum from farmed and wild Atlantic salmon. Aqueous humor results for farmed salmon are 2 pooled samples each from 5 fish, for wild salmon pooled samples from 4 to 5 fish. Values are in $\mu \mathrm{mol} \mathrm{l}^{-1}$, except for protein $\left(\mathrm{g} \mathrm{l}^{-1}\right)$

\begin{tabular}{|lcc|}
\hline Component & Farmed salmon & Wild salmon \\
\hline Aqueous humor & & \\
Total protein & $3.30 / 3.80$ & 2.64 \\
Ascorbic acid & $43 / 50$ & 57 \\
Uric acid & $4 / 5$ & 2.9 \\
Tryptophan & Trace/8 & 18 \\
Tyrosine & $47 / 42$ & 74 \\
Plasma & & \\
Ascorbic acid & $150 / 146$ & $170 / 204$ \\
Uric acid & $8 / 7$ & $108 / 95$ \\
\hline
\end{tabular}

Formalin-fixed eyes were subsequently opened under a Leica MZ 125 dissection microscope by cutting a medial and lateral calotte, and lens changes were recorded with a Leica DC100 digital camera. The sagittal ring with the lens was then dehydrated in ascending concentrations of ethanol and embedded in paraffin. Sections of 3 to $5 \mu \mathrm{m}$ were stained with haematoxylin and eosin. Material from 2 lenses was processed for transmission electron microscopy. Samples from the anterior cortex were postfixed in $2 \% \mathrm{OsO}_{4}$ in $0.1 \mathrm{M}$ cacodylate buffer, $\mathrm{pH} 7.2$, for $2 \mathrm{~h}$, dehydrated in ascending concentrations of ethanol and embedded in LX 112 Resin (Ladd Research Industries, Burlington, Vermont). Semithin sections $(1 \mu \mathrm{m})$ were stained with toluidine blue. Ultrathin (90 to $110 \mathrm{~nm}$ ) sections were mounted on copper grids, stained with uranyl acetate and lead citrate, and examined in a Philips 208 transmission electron microscope.

Findings were statistically evaluated with the JMP statistic package, Version 4.2 (SAS Institute). A 1-way ANOVA was used to determine if the presence of intraocular hemorrhage affected the cataract score, if there was a difference in the cataract score between trawlings, and if the cataract score affected the $K$ factor, i.e. Fulton's $K$, where $K=$ weight (standard length $)^{3}$. A chi-square test was used to determine if there was a difference in frequency of intraocular hemorrhage between trawlings. A result was considered statistically significant if $\mathrm{p}<0.05$.

\section{RESULTS}

All the postsmolts in the present study showed lens changes. Apart from 3 fish with unilateral minor changes, the remaining 188 salmon examined displayed bilateral lens opacities. The opacities were clinically evaluated as osmotic cataracts, with a swelling of the lens fibres along the anterior vertical suture line (Fig. 1). The lens changes varied in extension from minor opacity to haziness of the whole anterior lens preventing examination of deeper lens structures. Small and/or large vacuoles within the areas of opacification were frequently observed (Fig. 2). Most lenses with Score 4 cataracts appeared swollen, filling out the aphakic crescent, which is normally visible through the pupil.

One or both eye bulbs were ruptured in 3 fish. Minor superficial corneal abrasions were seen in most fish. These were, however, epithelial or affected only the superficial stroma; they did not penetrate the cornea, nor were they accompanied by corresponding lens changes. Fresh intraocular hemorrhages were diagnosed in 72 smolts. The hemorrhages varied from minute ventral accumulations of blood in the anterior 


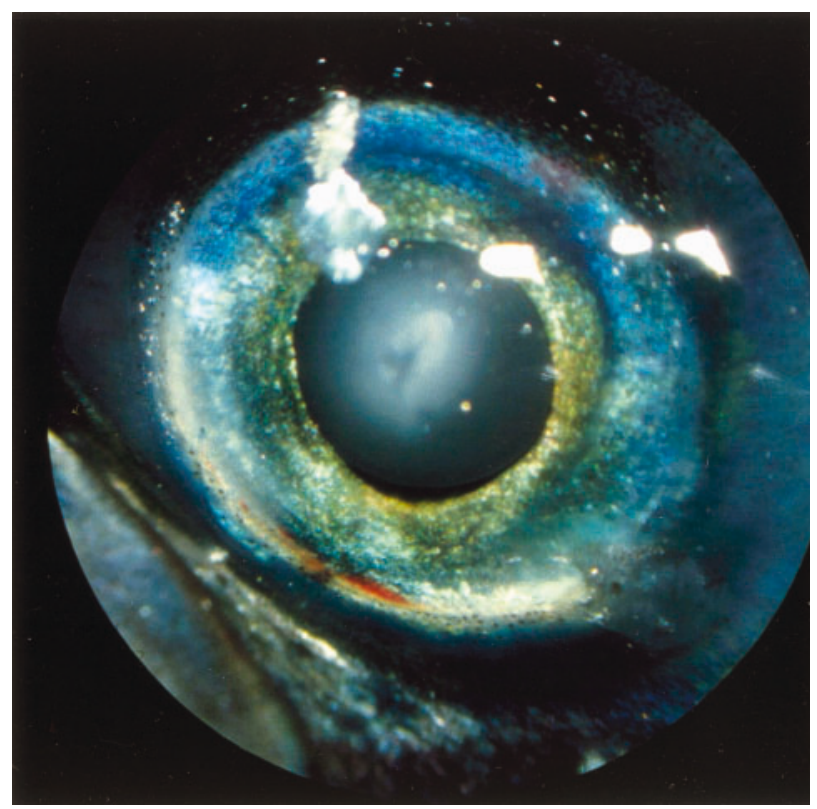

Fig. 1. Salmo salar. Osmotic cataract with cortical swelling outlining vertical anterior suture line. Small vacuole can be seen adjacent to suture line. There is some minor hemorrhage in anterior chamber

eye chamber that were only visible by slit-lamp examination to macroscopically visible hemorrhages. Of the 4 adult salmon examined, 1 had bilateral cataracts, manifested as large vacuoles within an otherwise clear lens (Fig. 3). None of the mackerels examined had lens opacities or other ocular changes.

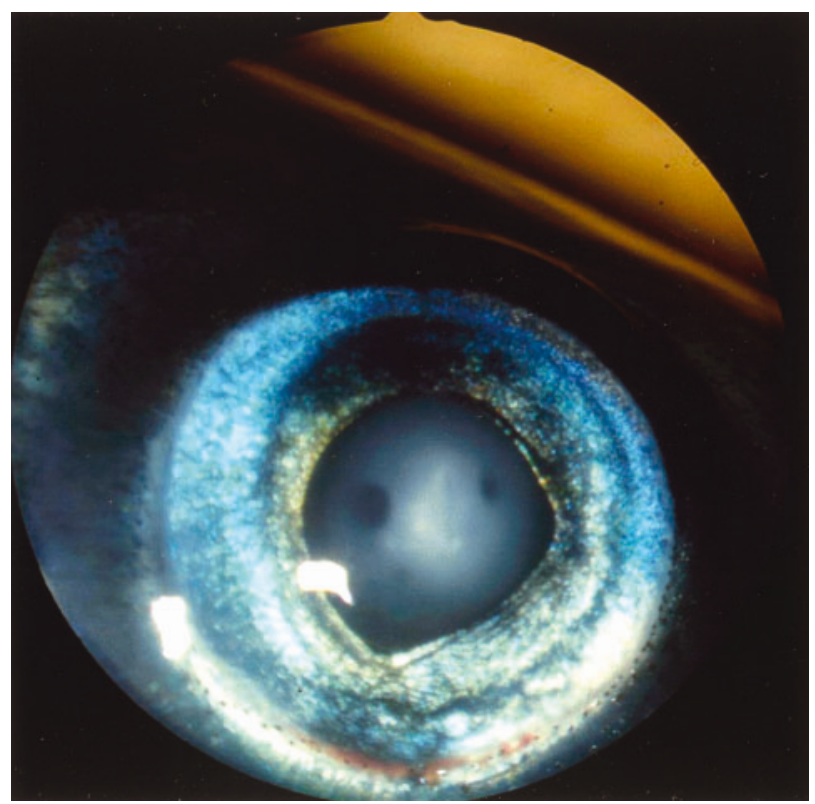

Fig. 2. Salmo salar. Osmotic cataract with vacuolation of cortex. Lens is swollen, filling the whole pupil

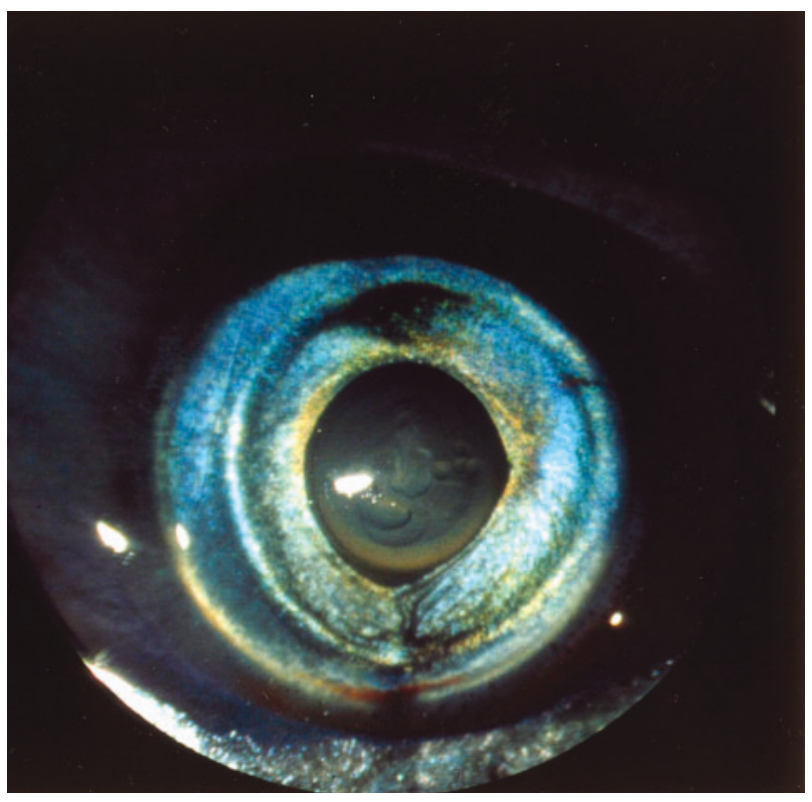

Fig. 3. Salmo salar. Adult with large, clear vacuoles in the lens cortex

The majority of the smolts had changes affecting 50 to $75 \%$ of the pupillary area when viewed straight through the lens. The mean cataract score for all examined smolts was 5.4 (standard error of the mean $=0.14$ ). There was no statistically significant difference in the severity of cataract changes in fish from the different trawlings ( 1 -way ANOVA, $p=0.55)$. There was a slight difference in frequency of intraocular hemorrhage between the trawlings; however, this difference was not statistically significant (chi-square, $p=0.06$ ). Intraocular hemorrhage did not affect cataract severity (1-way ANOVA, $\mathrm{p}=0.27$ ).

The mean length and weight of the postsmolts were $197.4 \mathrm{~mm}$ and $91.5 \mathrm{~g}$, respectively, with a mean $K$ factor of 1.15 ( $\mathrm{SD} \pm 0.09)$. The cataract score did not affect the $K$-factor (1-way ANOVA, p =0.67). A few sea lice Lepeophtheirus salmonis were found, and skin signs of attacks were seen in a number of the fish. However, none of the fish showed major skin lesions.

\section{UV-absorbance}

The compositions of the aqueous and plasma from farmed and wild salmon are shown in Table 1; the corresponding photometric curves are shown in Fig. 4. Biochemical analyses of aqueous humor and plasma revealed little difference between farmed and wild salmon. However, a higher level of plasma uric acid was found in wild salmon than in farmed salmon, although this difference was not reflected in aqueous 

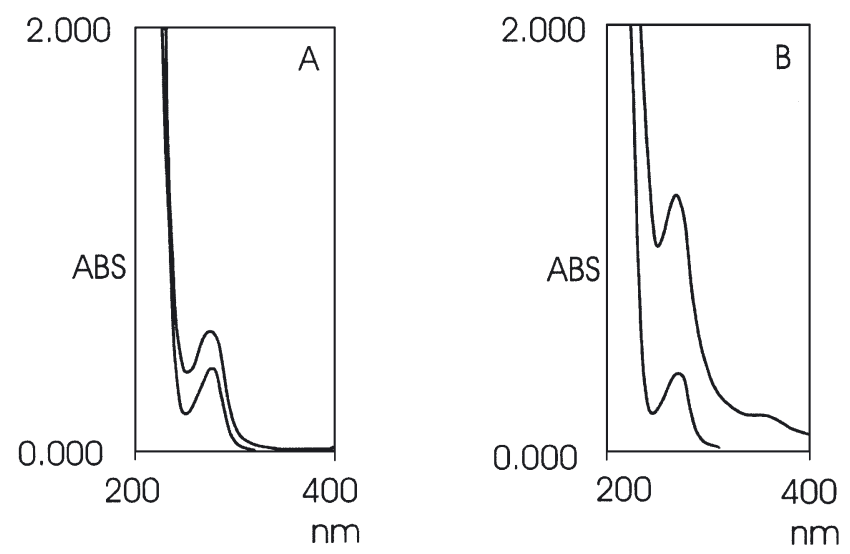

Fig. 4. Salmo salar. Photometric curves showing UV-absorbance (ABS) in (A) farmed and (B) wild postsmolts. Lower curves: mock aqueous humor; upper curves: native aqueous humor

humor levels. The UV-absorbance of the aqueous humor in the wild salmon was markedly higher than that of farmed salmon. Thus, mock wild salmon aqueous humor showed roughly the same absorbance pattern as mock and native farmed salmon, while native wild salmon seemed to contain an additional component responsible for increased absorbance. This factor has so far not been identified. cases the changes were present as varying degrees of vacuolation and swelling of fibre ends and widening of the suture. In some cases the suture could be traced through the whole cortex. In 2 cases there was extensive posterior swelling and necroses of the fibre ends, and the suture appeared as a wide wedge-shaped gap filled with proteinaceous material (Fig. 8).

Transmission electron microscopy of 2 smolt lenses revealed extensive vacuolation of the anterior superficial cortical area. The changes comprised dilated extracellular spaces and intracellular vacuoles (Fig. 9). The lenses were formalin-fixed, however, which is not optimal for electron microscopy, and the extent of intra- versus extracellular location of the changes could not be decided. The lens capsule and epithelium were lost during preparation in all sections and could therefore not be studied.

\section{DISCUSSION}

Lens opacities were diagnosed in all the examined wild salmon. The majority of the fish had changes affecting 50 to $75 \%$ of the pupillary area, i.e. opacities that cause visual disturbance. Visually incapacity is likely to result in reduced food uptake, and visually impaired postsmolts will also be an easy prey. This may affect the survival rate of postsmolts in the sea

\section{Microscopic examinations}

Under the dissection microscope, all smolt lenses exhibited an anterior hazy area, which in some cases contained large vacuolar formations. Widening of the anterior suture was evident in most cases (Fig. 5). Generally, the posterior suture was also very distinct, and a few lenses displayed a small posterior prominence and a widened and irregular suture. In histological sections, the mildest changes were a vacuolation of the epithelium and underlying superficial cortex. In some cases there were subepithelial lakes of proteinaceous material which, in 1 case, extended over most of the anterior hemisphere and was associated with swelling and necroses of underlying fibres (Fig. 6). Anterior epithelial proliferation was observed in 3 cases (Fig. 7). A single fluke, not associated with lens fibre changes, was seen in the posterior deep cortex of 1 lens with mild anterior changes. The fluke species was not further classified. Also in the posterior area, fibre vacuolation was a common finding. In most

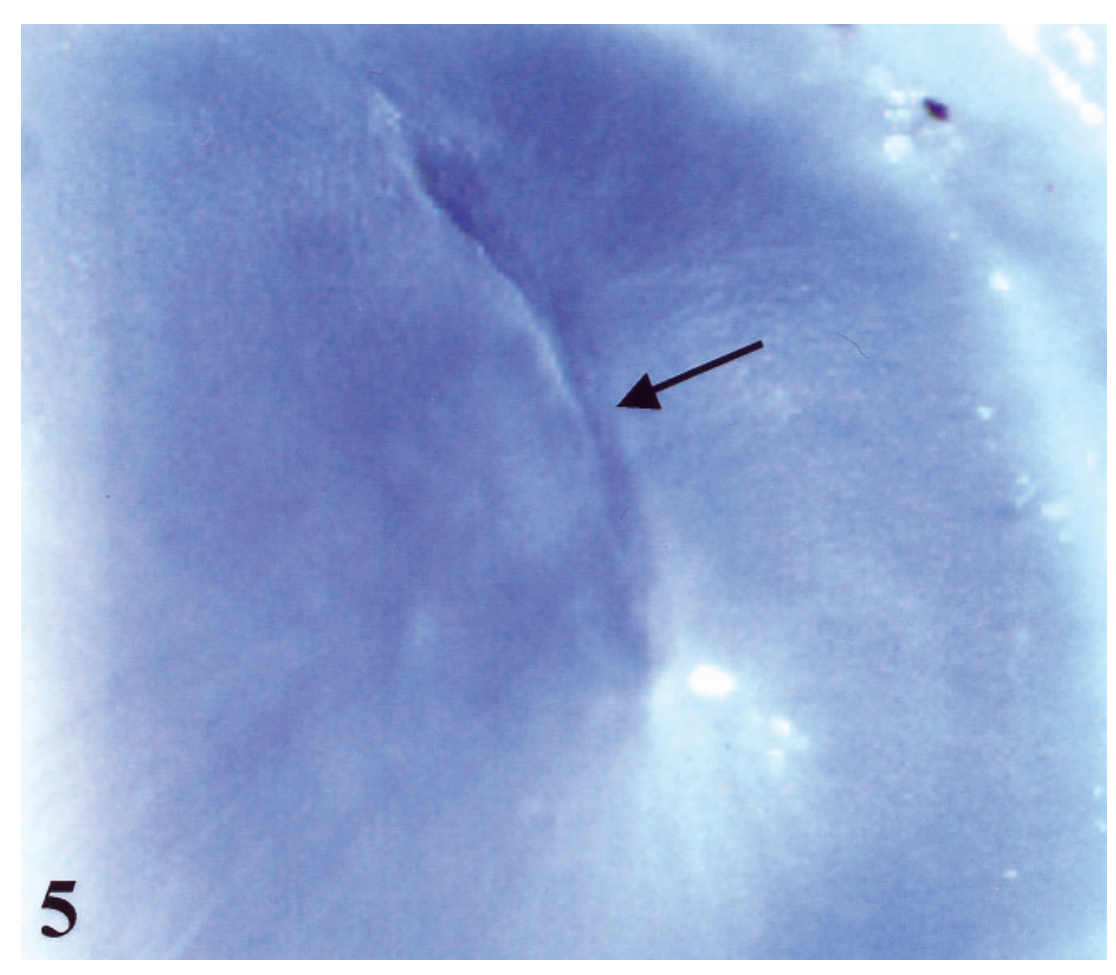

Fig. 5. Salmo salar. Dissection-microscope picture of anterior surface of formalinfixed lens showing widening of suture (arrow) $(\times 70)$ 

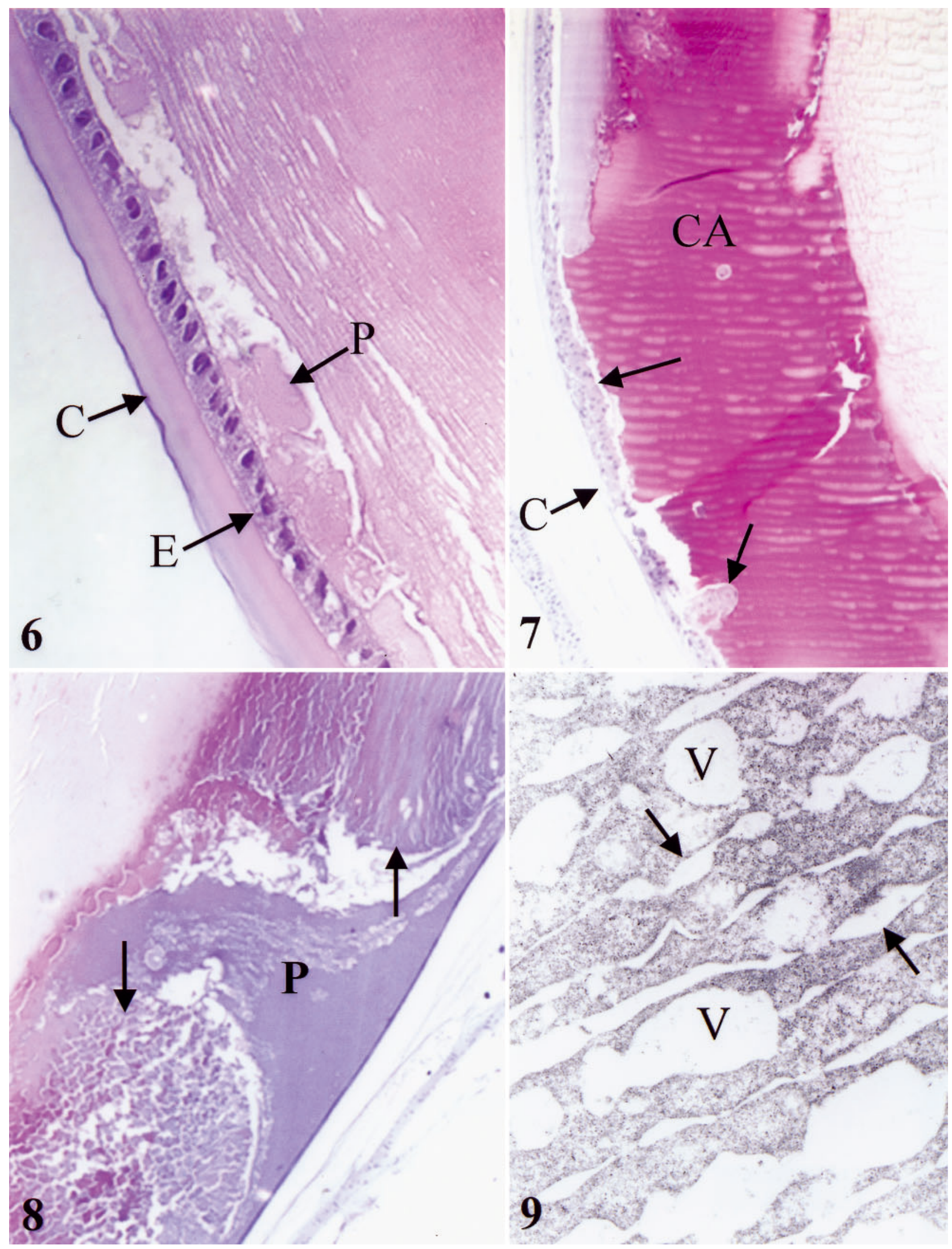
Figs. 6 to 9. Salmo salar. Fig. 6. Anterior area with proteinaceous lake (P) beneath lens epithelium (E) and finely vacuolated superficial cortex; C: lens capsule (H\&E $\times 490)$. Fig. 7. Epithelial proliferation (arrows) and cataractous changes (CA) in anterior cortex; C: lens capsule $(H \& E \times 115)$. Fig. 8. Proteinaceous material $(\mathrm{P})$ in area of posterior suture, and swelling of fibre ends

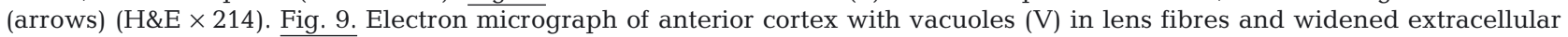
spaces (arrows); formalin-fixed material $(\times 10500)$

and, subsequently, the number of salmon returning to the rivers. However, at the present stage we are not in a position to further elucidate the role of cataracts as a population-regulating factor in salmon.

Salmon lice infestations have been considered a major cause of mortality in smolt from western Norwegian rivers. The breakdown of the epidermal barrier in heavily lice-infested fish is considered to cause increased osmotic stress and reduced survival rate, and a research program has been established by IMR to determine if salmon farms act as a reservoir for sea lice, which may infest wild salmon postsmolts during migration. It has been reported, however, that even smolt produced in areas where the detrimental effect of salmon lice is low, still do not return to the rivers to mate, as would normally be expected (J.C.H. pers. comm.). Factors other than salmon lice may therefore be also involved in the non-return of salmon to rivers. The lack of major skin lesions in the fish examined in our study suggests that the vast majority had not been exposed to severe lice attacks.

Based on the fish size observed and knowledge of the general migration paths of European postsmolt salmon (Holm et al. 2000), the fish caught in this study were considered to consist of a combination of mainly British and Norwegian stocks. As cataracts were found in all fish, the phenomenon seems not to be geographically restricted.

The fish lens is relatively hard, with a low water and high protein content compared to the mammalian lens (Ahrend et al. 1999). This may make it more susceptible to cataract formation, since protein aggregation is a cause of light-scattering. The metabolism and growth of the fish lens are affected both by factors in the water and by substances taken up through the digestive tract and converged in the aqueous humor.

The parr-smolt transformation entails a change from freshwater adaptation to seawater adaptation. During this stage, the salmon changes from hyperosmotic osmoregulation of water and ions in the body (ions are maintained in the body while water is removed) to hypoosmotic regulation (water is maintained and ions are removed). During parr-smolt transformation, hormonal changes initiated by hypothalamic regulation occur, as well as a marked increase in the activity of the ion $\mathrm{Na}^{+}-\mathrm{K}^{+}$-ATPase pump in the gills. This increase normally occurs when the fish adapt to seawater and is part of the development of hypoosmotic osmoregula- tion (Staurnes \& Stefansson 1998). Parr-smolt transformation is a critical period, and farmed salmon is considered to be especially susceptible to both osmotic lens changes and irreversible cataracts during this period (Breck \& Sveier 2001).

The majority of the postsmolts in the present study showed lens changes of an osmotic nature. Such lens changes may occur in farmed salmon shortly after seawater transfer if they have not been fully smoltified, but will disappear within less than 1 to 2 wk (O. Breck pers. comm.). The examined postsmolts are estimated to have entered seawater 4 to $10 \mathrm{wk}$ prior to catching. The histological changes found in the present fish were acute to subacute and consistent with this span of time. Based on the appearance of the lens changes, a reduced seawater tolerance with defective osmoregulation might be suspected as, once in the ocean, salmon should normally be able to adapt to the new environmental situation and regain transparent lenses. With time, the osmotic cataract would also be expected to diminish in some of the affected fish in our study. One of the adult salmon examined had bilateral cataracts presenting as large vacuoles, but not obscuring the vision significantly. It is possible that these lens changes represent former osmotic cataracts. Osmotic cataracts in salmonids have been extensively studied by Iwata et al. (1987). Coho salmon parr exposed to saltwater developed osmotic lens changes after 1 to $3 \mathrm{~h}$. Studies on the osmolality of aqueous humor compared to blood plasma showed that the osmolality of the former increased more rapidly than that of the latter. This indicates the possibility of an influx of electrolytes or loss of water directly through the cornea. In mammals, an active cation pump mechanism reduces water uptake into the eye through the cornea. This pump mechanism seems to be poor in fish (Poliquen 1999). Thus, changes in water salinity will affect the anterior part of the eye including the lens, which in fish lies adjacent to the inside of the cornea (Wilcock \& Dukes 1989). The cells of the lens fibre are normally maintained in a relatively dehydrated state by the action of the $\mathrm{Na} / \mathrm{K}$ pump. Changes in the $\mathrm{Na}, \mathrm{K}$ or $\mathrm{Cl}$ permeability of the lens or in its $\mathrm{Na}$ pump rate will, however, eventually alter the ability of the lens to control swelling (Rae 2001).

The histopathology of osmotic cataracts in fishes has not been extensively studied, but the changes re- 
corded in the present study, including swelling, vacuolation and disruption of lens fibres, as well as dilated extracellular spaces, are consistent with the osmotic disturbance of lens fibres (Phelps Brown \& Bron 1996). As the postsmolts were, in part, caught together with large numbers of mackerel, and some had suffocated during trawling, one might suspect the osmotic lens changes to have developed during the trawling period. However, the histopathologic changes also included cell necrosis of the lens fibres and large vacuoles, as well as anterior epithelial proliferation. These changes indicate a more protracted time of development. In addition, no lens changes were found in the mackerel examined; this would have been expected if the osmotic cataracts had been caused by mechanical damage.

Biochemical analyses of aqueous humor and plasma showed little difference between farmed and wild salmon, with one exception: plasma uric acid in wild salmon was markedly elevated compared to that in farmed salmon and to the normal plasma uric acid level in farmed postsmolts (given as 10 to $15 \mu \mathrm{mol} \mathrm{l}^{-1}$ by Ervik et al. 1987). It might be that the smolts in our study were sampled immediately after heavy meals, but it is also possible that the high value reflects metabolic stress with cell death and nucleotide degradation. The mean $K$-factor for the examined fish was not lower than expected (J.C.H. pers. obs.), and the cataract score did not affect the $K$-factor, indicating that the smolt has been able to find food despite poor vision.

Ultraviolet radiation has been discussed as a possible explanation for the lens opacities seen in postsmolts over the last years. UV-exposure seems to be $1 \mathrm{im}$ portant factor causing cataracts in humans (Cruickshanks et al. 1992), and experimental studies have shown the same effect in animal species also (Ayala et al. 2000). At the membrane level, UV radiation may inhibit $\mathrm{Na}^{+}-\mathrm{K}^{+}$-ATPase activity (Torriglia \& Zigman 1988). UV-induced cataracts in in vitro studies of pig lenses presented as clusters of discrete dots in the anterior subcapsular layer (Oriowo et al. 2001). UV radiation in rainbow trout resulted in cataract development, initially presenting as an anterior subcapsular opacity, later affecting either the lens cortex or presenting as a perinuclear haze. The UV-related cataracts were of an irreversible nature and could also be accompanied by corneal edema (Cullen \& Monteith McMaster 1993, Cullen et al. 1994). Thus, they were not consistent with the osmotic changes diagnosed in the fish in our study. The UV-absorbance of the aqueous humor in the wild salmon in our study was higher than that in farmed salmon. Still, it cannot be excluded that, although not a primary cause, oxidative stress caused by UV radiation may be a contributing factor to osmotic cataract development.
The causes of the osmotic cataracts observed in this study have not been identified. However, an effect of reduced or fluctuating water $\mathrm{pH}$ cannot be excluded. Acid water has been recognized as a problem for freshwater fishes in certain regions of Norway since the 1920s and has caused losses in fish populations in many Norwegian rivers (Staurnes et al. 1996). The Atlantic salmon is more sensitive to acid water than other naturally occurring salmonids in Scandinavia. Exposure of smolting Atlantic salmon to acid water has been shown to inhibit the increase in gill $\mathrm{Na}^{+}-\mathrm{K}^{+}$-ATPase activity that normally occurs during the parr-smolt transformation, hence reducing seawater tolerance (Staurnes et al. 1993). In parr, exposure to acid water alone does not affect gill $\mathrm{Na}^{+}-\mathrm{K}^{+}$-ATPase activities, whereas exposure to aluminium (Al) containing acid water causes reduced activity. In soft water low in organic matter (typical for acidified areas in Norway), high levels of Al together with low levels of calcium (Ca) are considered to be important to the toxicity of water (Staurnes et al. 1993). Liming of rivers to neutral $\mathrm{pH}$ has been standard procedure for many years (West Laboratory Services 2000); however, it has been demonstrated that mixing-zones of Al-rich acid water and limed or neutral water may be even more toxic to fish than the Al-rich acid water itself, with osmoregulatory failure as a major sign (Rosseland et al. 1992).

The lens changes observed in our study were considered to be osmotic cataracts, and it is suggested that the cataracts in the postsmolts studied were caused by defective osmoregulation. Cataracts caused by mechanical damage to the eye during trawling are less likely, based on both clinical and histopathologic studies and the fact that no opaque lenses were observed in the mackerel examined. Compromised osmoregulation has been shown to cause increased mortality in fishes (Staurnes et al. 1996). It cannot be excluded that sublethal environmental factors (primarily a moderate reduction or fluctuation in water $\mathrm{pH}$ ) may have been involved in the development of osmotic cataracts, with lens changes as the only visible sign of defective osmoregulation. Further studies are, however, necessary to clarify this aspect.

Acknowledgements. The authors thank Egil Jellum and Erlend Anderssen, National Hospital, Oslo, for performing the amino acid and the ascorbate/urate analyses, respectively. The staff on RV 'Johan Hjort' are thanked for assistance during sampling.

\section{LITERATURE CITED}

Ahrend M, Breck O, Wegener A, Breipohl W (1999) Crystallin patterns of normal and cataractous lenses of farmed Atlantic salmon from fresh water and seawater period. Investig Ophthalmol Vis Sci 40:302 
Anonymous (1986) Report of the meeting of the special study group on the Norwegian Sea and Faroes salmon fishery. Int Counc Explor Sea Comm Meet 1986/M:8

Ayala MN, Michael R, Söderberg PG (2000) Influence of exposure time for UV radiation-induced cataract. Investig Ophthalmol Vis Sci 41:3539-3543

Bjerkås E, Bjørnestad E (1999) Is there a connection between rapid fluctuation in water temperature and cataract development in the Atlantic salmon (Salmo salar L.)? Bull Eur Assoc Fish Pathol 19:166-169

Bjerkås E, Waagbø R, Sveier H, Breck O, Bjerkås I, Bjørnestad E, Maage A (1996) Cataract development in Atlantic salmon (Salmo salar L.) in fresh water. Acta Vet Scand 37:351-360

Bjerkås E, Bjørnestad E, Breck O, Waagbø R (2001) Water temperature regimes affect cataract development in smolting Atlantic salmon, Salmo salar L. J Fish Dis 24:281-291

Breck O, Sveier H (2001) Growth and cataract development in two groups of Atlantic salmon (Salmo salar L.) post smolts transferred to sea with a four-week interval. Bull Eur Assoc Fish Pathol 21:91-103

Cullen AP, Monteith-McMaster CA (1993) Damage to the rainbow trout (Onchorhynchus mykiss) lens following an acute dose of UVB. Curr Eye Res 12:97-106

Cullen AP, Monteith-McMaster CA, Sival JG (1994) Lenticular changes in rainbow trout following chronic exposure to UV radiation. Curr Eye Res 13:731-737

Cruickshanks KJ, Klein BE, Klein R (1992) Ultraviolet light exposure and lens opacities: the Beaver Dam eye study. Am J Public Health 82:1658-1662

Ervik A, Ellingsen HM, Farestveit E, Fløysand R, Ulriksen D, Waagbø R (1987) The effect of chronic ammonia exposure on growth, gill structure, blood chemistry and catecholamines on Atlantic salmon (Salmo salar) in seawater. Int Counc Explor Sea Comm Meet F:1-39

Hargis WJ (1991) Disorders of the eye in finfish. Annu Rev Fish Dis 1:95-117

Holm M, Holst JC, Hansen LP (2000) Spatial and temporal distribution of post-smolts of Atlantic salmon (Salmo salar L.) in the Norwegian Sea and adjacent waters. ICES J Mar Sci 57:955-964

Hughes SG (1985) Nutritional eye diseases in salmonids: a review. Prog Fish-Cult 47:81-85

Iwata M, Komatsu S, Collie NL, Nishioka RS, Bern HA (1987) Ocular cataract and seawater adaptation in salmonids. Aquaculture 66:315-327

Kerr JB, McElroy CT (1993) Evidence for large upward trends of UVB radiation linked to ozone depletion. Science 262: 1032-1034

Oriowo OM, Cullen AP, Chou BR, Sivak JG (2001) Action spectrum and recovery for in vitro UV-induced cataract

Editorial responsibility: Carl Schreck,

Corvallis, Oregon, USA using whole lenses. Investig Ophthalmol Vis Sci 42: 2596-2602

Phelps Brown N, Bron AJ (1996) Biology of cataract. In: Phelps Brown N, Bron AJ (eds) Lens disorders: a clinical manual of cataract diagnosis. Butterworth-Heinemann, London, p 91-132

Poliquen Y (1999) Corneal transparency in human beings and animals. Magrane lecture. Proc ECVO/ESVO/ISVO, p 8-12

Rae J (2001) Physiology of the lens. In: Tasman W, Jaeger EA (eds) Duane's ophthalmology 2001, CD-ROM edn. Lippincott Williams \& Wilkins, Baltimore

Reddy VN, Giblin FJ, Lin LR, Chakrapani B (1998) The effect of aqueous humor ascorbate on ultraviolet-B-induced DNA damage in lens epithelium. Investig Ophthalmol Vis Sci 39:344-350

Ringvold A (1996) The significance of ascorbate in the aqueous humor protection against UV-A and UV-B. Exp Eye Res 62:261-264

Ringvold A, Anderssen E, Kjønniksen I (1998) Ascorbate in the corneal epithelium of diurnal and nocturnal species. Investig Ophthalmol Vis Sci 39:2774-2777

Rosseland BO, Blakar I, Bulger A, Kroglund F and 6 others (1992) The mixing zone between limed and acidic river waters: complex aluminum chemistry and extreme toxicity for salmonids. Environ Pollut 78:3-8

Staurnes M, Stefansson S (1998) Smoltifisering (Smoltification). In: Hansen T (ed) Oppdrett av laksesmolt (Raising of salmon smolts). Landbruksforlaget, Oslo, p 25-48

Staurnes M, Blix P, Reite OB (1993) Effect of acid water and aluminum on parr-smolt transformation and seawater tolerance in Atlantic salmon, Salmo salar. Can J Fish Aquat Sci 50:1816-1827

Staurnes M, Hansen LP, Fugelli K, Haraldstad Ø (1996) Shortterm exposure to acid waters impairs osmoregulation, seawater tolerance, and subsequent marine survival of smolts of Atlantic salmon (Salmo salar L.). Can J Fish Aquat Sci 53:1695-1704

Torriglia A, Zigman S (1988) The effect of near-UV light on Na-K-ATPase of the rat lens. Curr Eye Res 7:539-548

Waagbø R, Bjerkås E, Sveier H, Breck O, Bjerkås I, Bjørnestad E, Maage A (1996) Nutritional status assessed in groups of smolting Atlantic salmon, Salmo salar L., developing cataracts. J Fish Dis 19:365-373

Wall T, Bjerkås E (1999) A simplified method of scoring cataracts in fish. Bull Eur Assoc Fish Pathol 19:162-165

West Laboratory Services AS Tananger, Norway (2000) Kalking av surt vann. Annual Report, 1-29

Wilcock BP, Dukes TW (1989) The eye. In: Ferguson HW (ed) Systemic pathology of fish. Iowa State University Press, p 168-194

Submitted: May 15, 2002; Accepted: March 25, 2003

Proofs received from author(s): June 11, 2003 